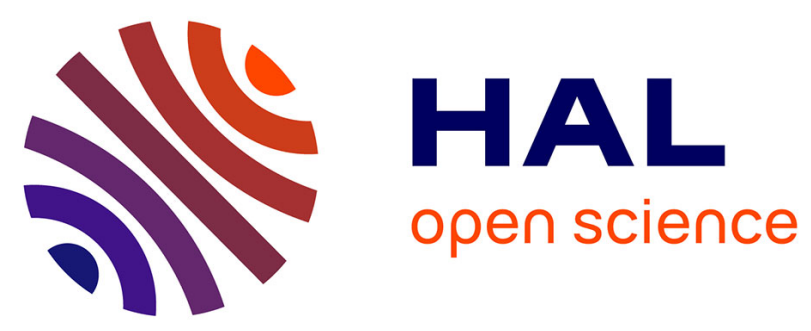

\title{
Speaking and Governing through Freedom of Access to Environmental Information
}

Melanie Dulong de Rosnay, Laura Maxim

\section{To cite this version:}

Melanie Dulong de Rosnay, Laura Maxim. Speaking and Governing through Freedom of Access to Environmental Information. Andrew Kenyon; Andrew Scott. Positive Free Speech. Rationale, Methods and Implications, Hart Publishing, Bloomsbury, pp.173-189, 2020, 9781509908295. hal02870479

\section{HAL Id: hal-02870479 \\ https://hal.science/hal-02870479}

Submitted on 16 Jun 2020

HAL is a multi-disciplinary open access archive for the deposit and dissemination of scientific research documents, whether they are published or not. The documents may come from teaching and research institutions in France or abroad, or from public or private research centers.
L'archive ouverte pluridisciplinaire HAL, est destinée au dépôt et à la diffusion de documents scientifiques de niveau recherche, publiés ou non, émanant des établissements d'enseignement et de recherche français ou étrangers, des laboratoires publics ou privés. 


\title{
Speaking and Governing through Freedom of Access to Environmental Information
}

\author{
MÉLANIE DULONG DE ROSNAY AND LAURA MAXIM
}

The principle of freedom of access to sanitary and environmental information produced by industry for regulatory purposes should enable citizens, NGOs, scientists and governments to check data and reassess substance toxicity risks. Through this, it supports opportunities to speak and to participate in the governance process. Under freedom of information laws, the ability to improve transparency, independently reassess risks and exercise free speech relies on the availability of data. However, access to environmental information is limited by companies' property rights, a source of legal exception to the principle of free access. Restrictions within environmental and sanitary information laws show commonalities with the field of information commons, in terms of access enclosure (trade secrets, confidentiality, intellectual property, data protection) and the conditions of producing effective free speech depending on the reusability of information (open data, open formats). This chapter examines the limits imposed by environmental law and regulatory practices on free speech, and considers institutional changes and the integration of open science and open data principles to improve both the governance of information produced by industry and its availability for the public to develop analysis and speech.

Access to environmental information was developed as a tool for governing environmental risks, and in particular chemical risks, in reaction to what was considered the failure of 'command and control' policies. The objective was to reinforce non-governmental stakeholders' information and hence power resources and capabilities to act to limit chemical risks by enabling attention-focusing free speech (for example, through public campaigns and press articles). Proponents of access to information-based environmental policies argued that such access could serve as an instrument to control pollution, because firms would want to reduce voluntarily their pollution figures in response to public scrutiny. ${ }^{1}$

Through access to information, governments intended to create a closer-to-level playing field for societal self-regulation. They intended to facilitate scrutiny of industry activities by NGOs, citizens and the press, and encourage changes in industry practices in response to information-based societal criticism. Access to information is thus a major landmark in the switch in environmental regulation towards the limitation of direct governmental

\footnotetext{
${ }^{1}$ JT Hamilton, Regulation through Revelation: The Origin, Politics and Impacts of the Toxic Release Inventory Program (Cambridge, Cambridge University Press, 2005).
} 
action on the private sphere, and the empowerment of other stakeholders to act on the industry through public speech. This policy trend joined that on public participation, which developed through the 1980s in response to repeated controversies over chemical pollution, and the exponential development of computing and digital technologies that facilitated the diffusion of masses of information to large audiences.

Highlighting the role of state regulators and society in science, the field of chemical risks provides an illustration of the asymmetry of power between industry and public health agencies or private stakeholders. The chemical industry is lobbying both legislators and regulators, the recipients of toxicity studies which condition access to markets, so that it can provide as little information as possible. The process of producing and communicating studies is expensive, and companies claim information on substances could reveal confidential and proprietary business information. ${ }^{2}$ Therefore, they ask legislators and regulators respectively to develop and implement restrictions on the amount and scope of information industry has to deliver, and on limiting access and reuse by third parties. Open science principles conflict with laws restricting access to results and information on health for financial interests ${ }^{3}$ and competitiveness. ${ }^{4}$

The lifecycle of data reveals possible bottlenecks at various stages: production by industry, collection by regulator, access by independent actors, reusability by regulator and independent actors, communication of results. The framework of negative and positive liberty is an effective instrument to guide our analysis of access to information throughout this lifecycle. ${ }^{5}$

The first section of this chapter examines how theories of positive free speech can be applied and can contribute to environmental legislation on access to information. We provide a critical assessment of the legal framework of access to information and its institutional settings in section II, before explaining which limits to free speech are impeding access and reuse in section III. In section IV, we consider conditions and options for the exercise of positive free speech towards a multiplicity of 'voices, ${ }^{6}$ also allowing a balance between transparency and other values and interests to produce better science supporting the development of safe products protecting the public interest. ${ }^{7}$

The chapter applies this discourse to the production of information on chemical risks, a field where both lobbyists' lawyers ${ }^{8}$ and academics reviewing case law $^{9}$ usually argue on the

\footnotetext{
${ }^{2} \mathrm{M}$ Bronckers and Y van Gerven, 'Legal Remedies under the EC's New Chemicals Legislation REACH: Testing a New Model of European Governance' (2009) 46 CML Rev 1823.

${ }^{3} \mathrm{~J}$ Conrad, 'Open Secrets: The Widespread Availability of Information about the Health and Environmental Effects of Chemicals (2006) 69(3) Law and Contemporary Problems 141.

${ }^{4}$ S Jasanoff, 'Transparency in Public Science: Purposes, Reasons, Limits' (2006) 69(3) Law and Contemporary Problems 21-45.

${ }^{5}$ I Carter, 'Positive and Negative Liberty' in EN Zalta (ed), The Stanford Encyclopaedia of Philosophy, Summer 2018 edn, https://plato.stanford.edu/archives/sum2018/entries/liberty-positive-negative.

${ }^{6} \mathrm{~J}$ Lichtenberg, 'Foundations and Limits of Freedom of the Press' (1987) 16 Philosophy and Public Affairs 329; AT Kenyon, 'Assuming Free Speech' (2014) 77 MLR 379.

${ }^{7}$ Jasanoff (n 4).

${ }^{8}$ Conrad (n 3); Bronckers and van Gervens (n 2).

${ }^{9}$ See, eg J-L Laffineur, 'First ECJ Ruling on REACH: Choosing Registration over Exemption' (2010) 22 Journal of Environmental Law 135; L Squintani, 'Case Law of the Court of Justice of the European Union and the General Court: Reported Period 15.3.2015-31.8.2015’ (2015) 12 Journal for European Environmental \& Planning Law 379; L Squintani, 'Case Law of the Court of Justice of the European Union and the General Court: Reported Period 31.8.2015-31.12.2015' (2016) 13 Journal for European Environmental \& Planning Law 99.
} 
boundaries of the right to access, ${ }^{10}$ on legal exceptions to the duty to produce information and on legal exceptions to the right of access, as discussed in section III.

\section{Freedom of Access to Information as a Basis for Speech}

In this section, we explain how both the 'absence of obstacles, barriers or constraints' and the 'possibility of acting' are applied to access to information. ${ }^{11}$ Sections II and III will present the legal framework and obstacles to access, and section IV will present experiences and possible options to develop autonomy and speech. Progress can be achieved not only by decreasing legal limitations (as double negative liberty) on access to information impeding the production of speech, but also by actively supporting (as positive liberty) the production of appropriate information that could be expected to lead to good decisions. ${ }^{12}$

As theorised by Lichtenberg for freedom of press, ${ }^{13}$ free speech is limited and constrained by the property rights of others, while the ability to publish is the condition of exercise of positive free speech. The principle of freedom of access developed to enable positive free speech is indeed facing restrictions to access based on property rights held by industry. As 'free speech is commonly seen in negative terms as a limitation on government action that restricts speech, ${ }^{14}$ counter-lobbying for the absence of exceptions or barriers, which can be seen as a negative liberty, is only a first step to improve access and positive liberty. Another way to envision free expression and reframe the debate on access to environmental information in positive terms is not only based on the absence of restrictions on access to the material. The possibility of autonomy, beyond the unrestricted availability of relevant data for effective reuse, requires 'an obligation to act' on the part of the government, ${ }^{15}$ understood in our case study as legal obligations for both the legislator and an empowered regulator to support free speech.

The principle of access to information is established in international conventions, and European and national laws. In principle, the public may access information held by public authorities and previously produced by industries and provided to health and safety agencies for regulatory purposes, or to authorise or deny market access to substances based on toxicology studies. Consumers and workers may also directly access certain information held by industries.

Freedom of information, one of the foundations of the right to access, together with the right to health, implies the capacity to check reports and data independently, and to reassess risks to health and the environment. As underlined by Gelber's interpretation of Nussbaum's 'capabilities approach', being able to have good health and to exercise political speech are items on a list of 10 capabilities. ${ }^{16}$ According to a negative approach to freedom of speech,

\footnotetext{
${ }^{10}$ J Wates, 'The Aarhus Convention: A Driving Force for Environmental Democracy' (2005) 2 Journal for European Environmental \& Planning Law 2.

${ }^{11}$ Carter (n 5).

${ }^{12} \mathrm{C}$ Abbot and M Lee, 'Economic Actors in EU Environmental Law' (2015) 34 Yearbook of European Law 26.

${ }^{13}$ Lichtenberg (n 6).

${ }^{14}$ Kenyon (n 6) 379.

${ }^{15}$ ibid.

${ }^{16}$ K Gelber, 'Nussbaum's Capabilities Approach and Freedom of Speech' in F Panzironi and K Gelber (eds), The Capability Approach: Development Practice and Public Policy in the Asia-Pacific Region (London, Routledge, 2012) 38 (quoting Nussbaum's 2006 list).
} 
the government should only 'refrain from interfering': in our case, it would not devise access to information legislation, and would allow the market to decide the amount and level of information which was provided without endangering property rights and innovation. A positive approach for Gelber would, on the contrary, create public policy that 'enhances' the opportunity for a range of entities to speak.

Peer review of data, methodologies and results is an essential part of the scientific process. This is all the more so in a context of conflict of interest, since the industry sponsors studies to assess the risk of its own products and activities. ${ }^{17}$ This democratic process, connected to the principle of reproducibility of scientific results, is deemed to allow the public to review the regulatory process, the study in question and the data underlying it. Hence, the public should be in a situation to exercise free speech and be able to alert industry, media, NGOs, public opinion and/or public authorities of possible health and environmental concerns about products or activities. In order to be effective, freedom of expression, relying on freedom of information or the public right to know, requires informed participation. ${ }^{18}$ The industry is expected to deliver useful data in meaningful ways once the government has created a positive obligation:

Although the phrase the right to know is a useful generic designation, it is an inadequate description for the legal rights and obligations that govern the communication of workplace obligation on toxic substances. A person will not have a meaningful right to information unless someone else has a corresponding duty to provide that information. ${ }^{19}$

Ashford and Caldart further distinguish the duty to disclose, the duty to generate, the right of access and the duty to inform. Access on demand (pull) is different from online availability (push), with the latter being closer to a positive liberty. And because of restrictions based on copyright, the right of access does not necessarily include the right to reuse. If the right of reuse is not explicitly included in legislation on access to environmental information (or a generic law on freedom of access to and reuse of public sector information), actions of positive communication, such as republishing the results of toxicity studies or performing additional research mining several databases, can be impaired by copyright, legislative or contractual database rights of producers of information.

The construction of the right of access can clash with a negative space, created by exceptions to exclusive rights of the producers and owners of information. Law does not appear to be ensuring appropriate access, since open science is restricted by a phenomenon known as data sequestration. ${ }^{20}$ Online availability can also be seen as useless or dangerous according to some stakeholders, especially in light of potential 'big data' use of raw data for commercial competition, while the data to be made available is not about commercial information but toxicity. These stakeholders will favour the approach of disclosing on demand (not as a positive obligation) in order to know who is asking.

\footnotetext{
${ }^{17}$ D Michaels, 'Foreword: Sarbanes-Oxley for Science' (2006) 69(3) Law and Contemporary Problems 1.

${ }^{18}$ Jasanoff (n 4).

${ }^{19}$ NA Ashford and CC Caldart, Environmental Law, Policy, and Economics: Reclaiming the Environmental Agenda (Cambridge, MA, MIT Press, 2008) 775.

${ }^{20}$ Michaels (n 17).
} 


\section{Assessment of the Legal Framework for Access to Information}

The current European legal framework for access to information on health and environmental risks is scattered across: (i) sectoral regulation for health and environment (in Europe, the REACH Regulation, ${ }^{21}$ the Conventions of Aarhus ${ }^{22}$ and Troms $\varnothing,{ }^{23}$ and the Directive on access to environmental information ${ }^{24}$ ); (ii) the Regulation on access to public sector information (PSI) ${ }^{25}$ and freedom of information; and (iii) legislation on copyright, personal data and industrial property.

These pieces of legislation have different legal foundations (human rights, the right to know, safety and protection of human health and environment, but also innovation and competitiveness) and enforcement schemes. This can make it difficult for agencies, NGOs and citizens to understand which regime to invoke and how to use it. Small NGOs, scientists and citizens also report difficulties in terms of accessing data to be able to exercise free speech and review or comment on such data, such as studies performed by the industry. As a consequence, public involvement in the governance of risks within agencies has been identified as limited compared to the involvement of industry. ${ }^{26}$ The effectiveness of access to information is determined by specific regulatory and institutional contexts. The entanglement of multiple laws does not clarify the situation or simplify the processing of making claims.

\section{A. Environmental Law in the USA}

While the focus of this chapter is European law, an incursion into US law helps to outline the general model that has subsequently been influential worldwide. The first high-profile regulation having access to information at its core was the Emergency and Community Right to Know Act of 1986. This was adopted in the USA two years after a release of methyl isocyanate at the Union Carbide chemical plant in Bhopal, India. The accident killed more than 2000 people. Industrial facilities were required to report yearly to the US Environmental Protection Agency the quantities of their toxic releases of certain substances. This information was then published in the USA's first publicly accessible database of its type: the Toxic Release Inventory (TRI).

Analysis of this regulation showed that access to information was effective and successful in reducing pollution only when the larger context included many other favourable factors.

\footnotetext{
${ }^{21}$ Regulation (EC) No 1907/2006 of 18 December 2006 concerning the Registration, Evaluation, Authorisation and Restriction of Chemicals (REACH) [2006] OJ L396/1.

${ }^{22}$ United Nations Economic Commission for Europe (UNECE) Convention on Access to Information, Public Participation in Decision-Making and Access to Justice in Environmental Matters, 1998.

${ }^{23}$ Convention of the Council of Europe on Access to Official Documents, 2009 (CETS 205).

${ }^{24}$ Directive 2003/4/EC of 28 January 2003 on Public Access to Environmental Information and Repealing Council Directive 90/313/EEC [2003] OJ L41/26.

${ }^{25}$ Directive 2013/37/EU of 26 June 2013 amending Directive 2003/98/EC on the Re-Use of Public Sector Information [2013] OJ L175/1.

${ }^{26}$ Abbot and Lee (n 12).
} 
In the case of TRI, it depended, among other things, on the knowledge of the programme among companies, the degree to which environmental information was circulated to investors, the political colour of the state and federal political majorities at a given time, the likelihood of collective action against polluters, the awareness of the community bearing the risks and even fears about the use of information by terrorists. ${ }^{27}$ As expected, the information has been used by environmental groups to exercise free speech and pressure firms for reductions in pollution, and by legislators for changes in environmental policies.

Another example of early access to information-based chemical policy is the Toxics Use Reduction Act (TURA). Adopted in the state of Massachusetts in 1989, this scheme aimed to change production processes and to reduce the use of toxic substances, and hence the quantities of toxic wastes produced, by companies. Its ambition was to reduce the quantity of toxic wastes in Massachusetts by 50 per cent within 10 years, using a strategy of public communication of information provided by companies and technical support to companies to identify possible improvements in their production processes. The scheme comprised positive actions to generate public speech and awareness.

Industry had a unique responsibility to identify the use of a range of substances listed by the public authority, and - when a given threshold was exceeded - to submit to the Department of Environmental Protection a plan for waste reduction. This policy was clearly a success: having involved more than 943 companies, it led to a 40 per cent reduction in the quantity of toxic wastes between 1990 and 2005 and saved millions of dollars for the companies involved (eg through limiting operating costs by reducing both raw material and waste disposal/treatment costs). However, the 'right to know' did not play its expected role in TURA. Even if, theoretically, any individual could obtain the data collected from the industry, no one successfully used this mechanism. ${ }^{28}$ The public did not play its expected role of applying pressure to motivate companies, and the factors that most probably led to success were the economic interest of companies in reducing the costs of managing their waste and the personal relationships that public administrators created with the local industry. This concurs with the findings in relation to the TRI, which related the effectiveness of access to information to a larger political process, in which many other favourable factors needed to be involved.

\section{B. In Europe: REACH Institutional Settings to Produce and Share Data}

Since the very beginning, REACH was conceived as a regulation that would produce information about chemical risks. The 'existing and new chemicals' regulatory framework that preceded REACH required a risk assessment for any 'new' chemical released to the market. For the 100,106 'existing' chemicals (those put on the market before 1981 and listed in the European Inventory of Existing Commercial Chemical Substances), the public authorities had to determine whether there was a need for examination and, if so, to conduct the

\footnotetext{
${ }^{27}$ Hamilton (n 1).

${ }^{28}$ D O’Rourke and E Lee, 'Mandatory Planning for Environmental Innovation: Evaluating Regulatory Mechanisms for Toxics Use Reduction' (2004) 47 Journal of Environmental Planning and Management 181.
} 
necessary assessment. From 1993 to 2001, however, only 141 high-volume chemicals were singled out for risk assessment and the procedure was accomplished for only 27. By 2004, only four further assessments were implemented under Community legislation. REACH was thus intended to address to the enormous informational gap created by the underdevelopment of the earlier regime.

Limited financial resources were the main reason for the failure of the 'existing and new' chemicals regulation before REACH. REACH sought to change this by requiring a company that would benefit commercially from selling a substance, also to pay the costs of testing its risks to humans and the environment. Hence, REACH led to the placing of the burden of proof on industry: the 'no data, no market' principle. Whereas the principle of placing the burden of proof on industry seems both pragmatic (for reasons of availability of information about the substance) and equitable (for the distribution of the testing effort between public and private arenas), however, the institutional setting created for producing and sharing data is at the core of the current difficulties of accessing information. This hampers the implementation of REACH in line with its original ambition. This institutional setting gives all the responsibility for data production to the industry, even if other options might have been possible, such as the charging of a public agency with gathering the information and requiring financial contribution from the industry. ${ }^{29}$ Alternative approaches could have better secured accountability, a recurrent problem identified by both the industry and NGOs. ${ }^{30}$

\section{Limits to Access to Information}

The law is not effective in ensuring appropriate access to and reuse of information, as identified by Michaels ${ }^{31}$ and explained by the authors in a previous short paper. ${ }^{32}$ In this section, we identify limits to the right of access, which in turn impair the exercise of freedom of speech.

\section{A. Procedural Limits}

Beyond the issue of conflicts of interest (industry is asked to produce 'objective' data about the risks of its own substances, data which is also used to regulate the industry), data production by industry creates several problems related to access to information. First, the regulatory authorities in charge of implementing REACH are dependent on the format in which data is provided by industry. For example, regulators may have access to the abstracts of studies performed by the industry but not to the full studies. For a correct appreciation of

\footnotetext{
${ }^{29}$ European Environmental Agency, Science and the Precautionary Principle: Lessons for Preventing Harm: Late Lessons from Early Warnings, vol II (Copenhagen, European Environmental Agency, 2013).

${ }^{30}$ See Bronckers and van Gervens (n 2) and Abbot and Lee (n 12), respectively.

${ }^{31}$ Michaels (n 17).

${ }^{32} \mathrm{M}$ Dulong de Rosnay and L Maxim, 'Lineffectivité du droit d'accès à l'information environnementale sur les risques chimiques' (2012) 64(3) Hermès: La Revue 149.
} 
the quality of data provided by industry, however, access to the full study is most often vital. The current procedure - in which authorities have to write a letter of demand to an industry actor, which has no obligation to respond - places the authorities in a weak position relative to industry players. Industry can choose whether or not to provide the full study. This opens the way to a negotiation, one which is necessary if authorities are to perform their regulatory role but in which industry has no motivation to provide the information demanded. Furthermore, negotiation can contribute to creating undue proximity between industry and its regulator.

Indeed, REACH promotes the principle of 'no data, no market', but neither 'no good data, no market' nor 'no full data, no market' is embodied in this principle. 'Some' data, be it partial and of low quality (sometimes studies several dozen years old are submitted by industry), is still 'data' and grants access to the market, unless the authorities are capable of reversing the evidence. Paradoxically, the regulation thus creates a situation in which the public authorities are disadvantaged in a power balance with the industry, as they cannot regulate substances that are potentially dangerous based on available information without being able to produce a sufficient level of proof of danger. Yet, to produce such levels of proof, public authorities need access to the widest information possible, including full industry studies.

Secondly, when data is lacking, a public authority cannot simply demand a new study from industry. Rather, it has to demonstrate, often based on very scarce information only, that existing studies are insufficient and that producing new ones is both scientifically justified and proportional to allow a decision. Despite the original declared ambition of reversing the burden of proof by requiring producers and consumers to communicate information on toxicity, in reality REACH continues to put the burden of demonstrating the risk of a substance on regulators.

Thirdly, high-quality information is also essential for limiting the impacts of chemicals on human health and the environment. Poor-quality scientific results can support poorquality decisions that fail to identify and limit risks that are nevertheless real. Most of the registration dossiers submitted by industry, however, do not respect the regulatory requirements. A report evaluating the registration dossiers for substances with a production volume of at least 1000 tons showed that 58 per cent of the screened dossiers were deficient in terms of the REACH information requirements. ${ }^{33}$ This was mainly because the test material did not correspond to the registered substance, and studies were not conducted in accordance with the appropriate guidelines. Only one dossier was found to be compliant, while no firm conclusion was reached in relation to 42 per cent of the dossiers.

In other words, who produces the information, the institutional setting for its transmission from private to public stakeholders, the quantity, the quality and the specific form of the environmental and health information are all directly relevant to guaranteeing effective reuse. The general public is not the only stakeholder for whom such access is challenging. In REACH, public authorities need good-quality and complete information owned by the industry in order to regulate, but lack the regulatory means to obtain such information. The current regulations on access to information focus on access by the public to information

\footnotetext{
${ }^{33}$ A Springer, H Herrmann, D Sittner, U Herbst and A Schulte, REACH Compliance: Data Availability of REACH Registration. Part 1: Screening of chemicals > 1000 tpa (Berlin, Bundesinstitut für Risikobewertung, 2015).
} 
held by public authorities. But access by public authorities to information on health and environmental risks - directly relevant for public health but produced and owned by private stakeholders - is also essential. It represents the condition sine qua non both for the protection of public health and for the access of the public to information on risks.

\section{B. Access to Information Depends on its Communication Format and Tools}

Three forms of direct communication to the public have been envisaged in REACH: first, on demand from the European Chemicals Agency (ECHA); secondly, online on the ECHA's website, which contains some freely available information from the registration dossiers; and thirdly, on demand from the industry. Any consumer can ask any supplier if their products contain Substances of Very High Concern (SVHC) that are listed on ECHA's Candidate List. These substances have been identified as carcinogenic, mutagenic or toxic for reproduction, as persistent and bioaccumulative, or as warranting similar concern. Suppliers are legally obliged to provide an answer with at least the name of the SVHC, and information allowing safe use of the article, within 45 days, free of charge, if the substance is contained in a proportion of more than 0.1 per cent in the article in question.

These two forms of direct communication are examined in turn here.

EU citizens should have access to information about chemicals to which they may be exposed, in order to allow them to make informed decisions about their use of chemicals. A transparent means of achieving this is to grant them free and easy access to basic data held in the Agency's database, including brief profiles of hazardous properties, labelling requirements and relevant Community legislation including authorised uses and risk management measures. ${ }^{34}$

For the ECHA's website, whereas the objective is to communicate information to the general public, in practice the form of this information and the functionalities of the tool render it difficult. The tool is adapted to a level of understanding of a scientifically highly educated 'public', able to understand technical toxicological and physicochemical data, mastering the chemicals denominations, and having a clear idea about the link between certain substances and their use in daily life. Furthermore, the public targeted by the tool is expected to understand technical English.

The ECHA has attempted to improve its communication of chemical information. Since 2016, presentation of information on up to 120,000 chemicals is structured in three layers: InfoCard, brief profile and detailed source data. The InfoCard is a dissemination tool that is intended to make the technical information published in the ECHA's substance databases more accessible to the general public, but the information still remains highly technical and synthetic. For the example of bisphenol A, a substance which has been highly debated worldwide for more than 20 years, the InfoCard does not include any harm prevention measures available to consumers, but only those suggested by manufacturers and importers that are oriented to their own employees and downstream users (ie companies or individuals using chemicals in their industrial or professional activities).

\footnotetext{
${ }^{34}$ REACH (n 21) Art 117.
} 
Figure 1 Partial screen shot of results for the search of the substance 'bisphenol A' on the ECHA's home page (11 May 2017)

\begin{tabular}{|c|c|c|c|c|c|}
\hline \multicolumn{6}{|l|}{ Search for Chemicals } \\
\hline \multicolumn{3}{|l|}{ bisphenol A } & \multicolumn{3}{|r|}{ Search } \\
\hline \multicolumn{5}{|l|}{$\checkmark$ I have read and I accept the legal notice } & ADVANCED SEARCH > \\
\hline Page 1 of $4 \longrightarrow 50$ Items per Page $\rightarrow \mathrm{S}$ & Showing 1 . 50 of 175 results & & - First & Previous & Last $\rightarrow$ \\
\hline Name $\hat{~}$ & $\frac{\mathrm{EC} / \text { List }}{\mathrm{no} \text {. }}$ & CAS no. $\mathrm{P}$ & & & \\
\hline $\begin{array}{l}\text { 4,4'-isopropylidenediphenol } \\
\text { Bisphenol A; BPA } \\
\text { Process related name: bisphenol A }\end{array}$ & $201-245-8$ & $80-05-7$ & 타 & & \\
\hline $\begin{array}{l}\text { 4,4'-Isopropylidenediphenol, oligomeric } \\
\text { reaction products with 1-chloro-2,3- } \\
\text { epoxypropane } \\
\text { IUPAC name: bisphenol A }\end{array}$ & 500-033-5 & $25068-38-6$ & EP & & \\
\hline Bisphenol A diphosphate & $605-913-3$ & $181028-79-5$ & & & \\
\hline Bisphenol A Epoxide & $921-634-2$ & - & & & \\
\hline Bisphenol A Epoxy & $918-654-9$ & - & & & \\
\hline
\end{tabular}

The Brief Profile summarises non-confidential data on substances held in the ECHA databases, but the website warns that this information is automatically generated and therefore may not be fully up to date or complete. Indeed, the data included is only that submitted by the registrant company.

As for access to information on demand directly from the suppliers of articles containing Substances of Very High Concern, a report produced by European Environmental Bureau showed that it remained largely unapplied. ${ }^{35}$ Of 158 'right to know' requests sent to 60 brands in Europe, 50 per cent remained entirely unanswered, while over 75 per cent received answers that did not fulfil REACH requirements.

\section{Access to Information Depends on the Power Balance that is in Place}

Besides the generic framework for access to environmental information stipulated in the Aarhus convention to support 'environmental democracy, ${ }^{36}$ each specific regulation creates the conditions for the exercise of this right. As discussed above, REACH is a typical example of compromise-based policy. It prolongs the trend in the environmental regulation, and in self-regulation in general, to influence industry's practices through continuous negotiation and persuasion rather than constraints (which are hard to implement in any event).

\footnotetext{
${ }^{35}$ European Environmental Bureau, The Fight to Know? Substances of Very High Concern and the Citizens' Right to Know Under REACH (Brussels, European Environmental Bureau, 2010).

${ }^{36}$ Wates (n 10).
} 
Behind the apparently strict rules of REACH, the complexity of chemical risks and the unequal capacities of public authorities and industry to produce information lead to implementation that strongly depends on communication and agreement between these two parties. This has two consequences for access to information for NGOs and the public. First, as compared with relationships with other stakeholders, there is a privileged relationship between public authorities and industry. Without communication with industry, concrete implementation of the regulation is impossible. Secondly, public authorities are overloaded due to the complexity of REACH, and have little time remaining for other duties such as communication to the public. In addition, some authorities may consider time invested in public communication to be less useful and effective in terms of public health than their main mission, which is the implementation of the regulation.

Even with its more than 500 pages, REACH cannot cover all the potential situations that may appear during its implementation, often dependent on the substance addressed and the industry concerned. Therefore, a pragmatic 'jurisprudence' comes into being during implementation. Informal rules based on experience, agreed between the public and private stakeholders, become standards for further similar situations and substances. Access to such informal rules and information thereon is possible only for stakeholders that are directly involved in the process of implementation, such as employees of, and experts working with, public authorities (ECHA, health and environmental agencies of Member States, national ministries) and the industries concerned. In addition to public access, some NGOs can be granted access to information directly through procedures specifically dedicated to participation in ECHA's work. Such interaction with stakeholders is directed to accredited NGOs, which, in terms of exercising access to information, have advantages in terms of direct contact with ECHA and access to informal information produced during the implementation process. The downside of such participation is that NGOs that are accredited by ECHA for participation have to work within the logic of compromise. ${ }^{37}$ Potentially, this may limit their propensity to use information for frank criticism and effective free speech.

Whereas access to information increases the capability of non-governmental stakeholders to act, the initial objective of controlling industry action through the empowerment of such stakeholders remains a myth. The forces in place are largely unbalanced; ${ }^{38}$ the human competences and financial resources available to industry to produce and control information are significantly greater than those of NGOs. ${ }^{39}$ Furthermore, access by industry to public regulators is significantly easier, given that regulation makes industry the main discussion partner for governmental health agencies.

\section{Substantial Limits}

Alongside procedural limits on rights of access to and reuse of information, a series of substantive limits also impede such engagement. These include the confidentiality of business information, successful contentions that information obligations serve as barriers to

\footnotetext{
${ }^{37}$ See http://echa.europa.eu/about-us/partners-and-networks/stakeholders.

${ }^{38}$ For example, of the list of stakeholders accredited to work with ECHA, 71\% are industry associations.

${ }^{39}$ Abbot and Lee (n 12).
} 
trade, and the nature and contours of information that is required to be disclosed under regimes.

\section{E. Confidential Business Information}

Confidentiality is another obstacle that limits the scope of information that can be accessed. As explained in REACH:

[only] non-confidential information on chemicals is to be available, for example to allow those exposed to chemicals to take decisions as to the acceptability of the associated risks. Some information is accessible free of charge on the Agency's website, other information on request. However, the Agency may not disclose confidential company data.

The first exception to the general principle of access to sanitary and environmental information is stated in all access to information laws that foresee exceptions for confidentiality, trade secrets and intellectual property, without defining these notions or providing guidance for agencies on interpreting what may fall within the category of confidential business information. Thus, industry players have the option of claiming the protection of confidentiality and intellectual property rights to dismiss demands of access to information and/ or to oppose the publication or further distribution of information they are compelled to provide to regulatory agencies for evaluation and authorisation purposes. ${ }^{40}$

In practice, confidential data and data protected by intellectual property can be withheld by the industry, or redacted from documents delivered to the state agency and/or the public. Agencies have a duty to protect confidential business information. The ECHA website publishes evaluation decisions in 'non-confidential versions of the decisions originating from compliance checks and examination of testing proposals'. Hence, there is a risk of abuse of the confidentiality exception, which companies may interpret expansively and apply to environmental and health data without commercial interest or risk of competition (for example, to the results of a toxicity test).

\section{F. Restriction of Trade}

Notwithstanding its seeming laxity, REACH is the subject of stringent criticism by free trade advocates. Implementing its complex obligations is said to discriminate against non-EU manufacturers and non-EU World Trade Organization members. ${ }^{41}$ Chemical regulation requiring the disclosure of information is seen as a cost for industry, in the same way as they lobby against obligations such as information labelling requirements under consumer law. Similarly, in the field of data protection, the right to privacy is also seen as a barrier to trade by industry.

Producing information and providing access to this information is assimilated to a nontariff barrier to trade. This categorisation was seen in a leaked joint document prepared

\footnotetext{
${ }^{40}$ Bronckers and van Gervens (n 2).

${ }^{41}$ LA Kogan, 'REACH Revisited: A Framework for Evaluating Whether a Non-tariff Measure Has Matured into an Actionable Non-tariff Barrier to Trade’ (2013) 28 American University International Law Review 489.
} 
by the American Chemistry Council and European Chemical Industry Council for the purposes of the Trans-Atlantic Trade and Investment Partnership (TTIP) free trade agreement negotiations, and positive obligations may end up being diminished. ${ }^{42}$

\section{G. Nature and Contours of Information}

Sanitary and environmental information produced by industry to fulfil legal obligations to safety agencies to evaluate product risks before market approval include reports and underlying toxicological data. The breadth of the information to be produced and released to the public is subject to interpretation and negotiation. For example, studies may be based on too small a sample or be of too limited a duration, or results may be analysed using an inadequate statistical tool.

The analysis of toxicology studies related to pollution and human health requires access to the experimental protocols used in the studies. The assumptions in these protocols are crucial for evaluating possible bias or flaws in the study, and the need to rerun alternative experiments. Also, the regulatory requirements themselves - which resulted from negotiations between stakeholders and not from 'purely scientific' input - can be a source of uncertainty and even scientific flaws. For instance, in chemical risks assessment, research identified that a small dose rather than a large dose will be poisonous; ${ }^{43}$ therefore, the dosages chosen in testing will significantly influence the results. The level of information provided by the industry depends on the amount of the substance produced or imported. More information must be provided when higher tonnages of the substance are produced or imported, based on the assumption that higher tonnage means greater exposure and hence greater potential effects. ${ }^{44}$ The information that might be relevant for science (small quantities can be harmful) therefore contradicts such quantity-based legal requirements, which assume that larger quantities are necessarily more problematic.

Conflicts about the contours of the information to be communicated are also frequent. The first landmark case law on REACH helped define the scope of exceptions for polymers. ${ }^{45}$ Other rulings helped to shape the contours of the communication duties to ECHA and to consumers under $\mathrm{REACH} .{ }^{46}$ Seeking access to information on several products individually does not have the same impact as asking for information on a complex end product as a whole. In the ClientEarth case, two NGOs sued ECHA to force it to release tonnage information and exact production quantities in order to pressure companies to adopt safer alternatives and to help consumers make informed choices. The European Court of Justice concluded, however, that the 'ECHA was entitled to take the view that the disclosure of the precise tonnage of the substances registered would have undermined the commercial interests of the persons concerned. ${ }^{47}$

\footnotetext{
${ }^{42}$ American Chemistry Council-European Chemical Industry Council joint proposal enhancing US-EU chemical regulatory cooperation under TTIP: see http://ciel.org/Publications/CH_Pro.pdf; M Karlsson, 'TTIP and the Environment: The Case of Chemicals Policy' (2015) 1 Global Affairs 21.

${ }^{43}$ European Environmental Agency, Chemicals in the European Environment: Low Doses, High Stakes? (Copenhagen, European Environmental Agency, 1997).

${ }^{44}$ Laffineur (n 9).

45 ibid.

${ }^{46}$ Squintani (n 9).

${ }^{47}$ T-245/11 ClientEarth v European Chemicals Agency (ECHA) [2015] ECJ.
} 


\section{Institutional Changes to Develop Capacities}

The two previous sections revealed institutional, epistemological and legal limits on access to information and their consequences for the possibility, the effectiveness and the quality of subsequent public speech. In this section, we examine possible changes to the governance of risk-based access to information which could implement a positive approach to free speech, beyond the mere negotiations of its limits.

In the two parts of this section, we consider possible action points which require a positive action from the government:

- Developing the role of regulatory agencies and third parties to address some of the obstacles identified in the previous sections, as the process of maintaining secrecy is easily abused. ${ }^{48}$

- Applying open data and open science principles to environmental law.

\section{A. Developing the Role of Regulatory Agencies and Third Parties}

Unbalanced institutional settings and the definition and interpretation of confidentiality have both been identified as internal limits to effective access to information. Accountability for providing misleading information to the regulator and the public could be developed and a person could be designated to evaluate studies and methods, and to justify claims to confidentiality. ${ }^{49}$ This proposition, inspired by the quite different field of accounting regulation, would have some similarities with the possible ways to develop positive free speech as theorised by Gelber: seeking to limit harmful speech (understood as misleading information), if confidentiality, which is often claimed to maintain secrecy, is misused and therefore used in a harmful way. ${ }^{50}$

Meaningful and effective legislation on access to sanitary and environmental information could define confidentiality and commercial interest, and develop mechanisms - perhaps using third parties - independently to assess the legitimacy of claims of confidentiality for business information. If access to information is envisioned as a positive right, exceptions should be interpreted narrowly. An alternative option would be to entrust intermediaries trusted third parties - to anonymise reports or to remove confidential information from them. Techniques for anonymising parties in lawsuits could be developed for confidential business information, as often it is not the commercial aspect of the substance which is of interest in assessing the risk.

The interpretation of data and the ability of citizens to process it are keys to the assessment of the risk of substances. Increasing the power of agencies to communicate results and to mediate information on risks (as media, whistleblowers and academics would do) is a solution which could be endorsed by industry. It would be up to Member States to

\footnotetext{
${ }^{48}$ Michaels (n 17).

${ }^{49}$ ibid.

${ }^{50}$ Gelber (n 16).
} 
relinquish power to regulators such as $\mathrm{ECHA},{ }^{51}$ and to increase their budgets to transform them into such watchdogs to inform the public.

\section{B. Importation of Open Data and Open Science Principles into Environmental Law}

The double influence of open copyright policy and citizen science participatory projects can contribute to the development of positive free speech in the field of environmental law. Yet, unlimited transparency is not necessarily the best way forward. The field of science and technology studies provides a useful counterbalance to openness, participation evangelism and techno-idealism. First, the process of transforming data into relevant information and improving the capacities of citizens to speak and NGOs to challenge regulatory decisions is not straightforward. More data, even if it is better data, is not immediately transformed into actionable knowledge. Secondly, excessive transparency can be a source of continuing doubt: political decisions could be postponed, while facts are questioned over and over again. Jasanoff theorises that some 'black-boxing' - relying on Latour - is essential for robust claims, avoiding the 'manufacturing of uncertainty' for political ends. ${ }^{52}$

The mere right of access, or the right to read, does not amount to the right to mine databases and make new scientific findings from data produced by others (equivalent to a right to read by computers). Indeed, copyright can limit the effectiveness of freedom of information laws, in terms of reusing information obtained under them, beyond reading it. The 2013 revised directive on public sector information ${ }^{53}$ introduced a right to reuse documents which can be accessed under national access to documents laws. It only invites Member States to make more documents available in machine-readable and standard open formats: there are no compulsory provisions regarding the nature and the contours of information to facilitate scientific processing and peer-review by NGOs. Nevertheless, the experience of copyright licensing under generic freedom of information laws suggests that freedom of access to environmental information laws should include provisions to allow effective reuse and data processing, require open formats and prohibit, or make void, restrictive terms of use by databases producers.

There would be a risk of having access to data, but not being able to interpret it and not being able to make it speak to the public. A mere right of access, giving an illusion of transparency, is not sufficient. A right of reuse is also needed. Access to information, allowing reports to be read, is a necessary but insufficient condition for the exercise of speech. NGOs, and potentially citizens, need to be able to reproduce, republish and mine databases. According to open science principles, a genuine open access allowing others to reproduce experiments and to verify results requires legal and technical accessibility. ${ }^{54}$ According to

\footnotetext{
${ }^{51}$ Bronckers and van Gervens (n 2).

${ }^{52}$ Jasanoff (n 4); B Latour, Science in Action: How to Follow Scientists and Engineers through Society (Cambridge, MA, Harvard University Press, 1987).

${ }^{53}$ Directive 2013/37/EC (n 25).

${ }^{54}$ M Dulong de Rosnay, 'From Free Culture to Open Data: Technical Requirements for Open Access' in D Bourcier, P Casanovas, M Dulong de Rosnay and C Maracke (eds), Intelligent Multimedia: Sharing Creative Works in a Digital World (Florence, European Press Academic Publishing, 2010) 47.
} 
open data advocates, the right to read and the right to process and perform data mining ${ }^{55}$ and meta-analysis requires open, downloadable data formats.

Government can also nudge or prompt citizens to reuse the open data it retains. The French Minister of Environment's 2016 'roadmap' proposed to create a general supervisor for data within the ministry. This new role is expected to develop a culture of data, both within the ministry and within the public, and to empower citizens through the organisation of hackathons to analyse, visualise, process, mine and otherwise exploit and communicate available data to the public. ${ }^{56}$ Crossing boundaries across public policy and law is essential for developing the best practices for data producers to provide data which can be reused in meaningful ways.

\section{Conclusion}

Access to information should allow civil society to send critical feedback to industry on the risks of its substances and hence help regulators in managing those risks. The practice is far more complicated: access to information would at the first sight appear to be granted by existing legal texts, but numerous opportunities exist in practice for reducing access. Our analysis supports the conclusion that the practice of access to environmental information fails to reach its full potential, namely contributing to the protection of public health in Europe.

Policy debates rarely move along the lines from negative to positive speech, understood as the 'architecture' or conditions which allow speech to occur. Such an approach could also be applied to other heavily lobbied fields, such as intellectual property, where more time is spent legislating on the scope of exceptions than on the development of policies to support the development and release of information.

In the line of the introducing trusted third parties to receive business information and remove confidential information from it, a prospective approach to resolving conflicts on the disclosure of information could consist in applying commons-based governance models to the governance of information on chemical risks. Mandatory data sharing about substances within Substance Information Exchange Forums with other industry members working on similar substances is a mechanism which has raised opposition from the industry as the governance was not consensually negotiated by all members. ${ }^{57}$ Instead, such forums could be managed as 'common pool resources, with mechanisms allowing collective benefits sharing, monitoring of usages, surveillance of free riders and a range of sanctions. ${ }^{58}$ This approach has been conceptualised for microbial data. ${ }^{59}$ Sharing biological material and data on chemical risk are equally challenging, as they contain potential competitive

\footnotetext{
${ }^{55} \mathrm{P}$ Murray-Rust, 'The Right to Read is the Right to Mine', Open Knowledge Foundation Blog, 1 June 2012, https://blog.okfn.org/2012/06/01/the-right-to-read-is-the-right-to-mine.

${ }^{56} \mathrm{~L}$ Monnoyer-Smith, Rapport de préfiguration de la fonction de superviseur général des données du ministère de l'environnement (Paris, Ministère de l'Environnement, de l'Energie et de la Mer, 2016).

${ }^{57}$ Bronckers and van Gerven (n 2).

${ }^{58}$ E Ostrom, Governing the Commons: The Evolution of Institutions for Collective Action (Cambridge, Cambridge University Press, 1990).

${ }^{59} \mathrm{JH}$ Reichman, PF Uhlir and T Dedeurwaerdere, Governing Digitally Integrated Genetic Resources, Data, and Literature: Global Intellectual Property Strategies for a Redesigned Microbial Research Commons (Cambridge, Cambridge University Press, 2016).
} 
information. Managing to communicate data which is useful for science, without disclosing the commercial-only value, requires the protection of participants' commercial opportunities. But this has to occur in a manner that does not amount to intellectual property and claims of confidentiality disrupting the level of access needed to perform some types of research and toxicity control. Commons-based pool arrangements for science are capable of supporting both commercial and public interests, enhancing the opportunities of all parties to speak and produce meaningful data, and could be considered as desirable governance arrangements to manage information on chemical risks. 


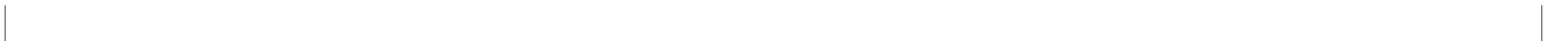

